\title{
Changing the Electrical Safety Culture
}

\author{
Benjamin Franklin $\mathbf{A}^{\mathbf{1}}$, Sasilatha $\mathbf{T}^{\mathbf{2}}$ \\ ${ }^{1}$ Research Scholar, Department of Electrical and Electronics Engineering (Marine), AMET University, Chennai \\ ${ }^{2}$ Department of Electrical and Electronics Engineering (Marine), AMET University, Chennai
}

\begin{tabular}{l}
\hline \hline Article Info \\
\hline Article history: \\
Received Jul 5, 2017 \\
Revised Nov 25, 2017 \\
Accepted Dec 18, 2017 \\
\hline
\end{tabular}

\section{Keywords:}

Behaviours

Beliefs

Electrical Safety

Evolution of Safety

Safety by Design

Safety Culture

Training Non-Electrical

Personnel

\begin{abstract}
Electrical wellbeing - Where were we yesterday? Where are we today? Where will we be later on? The wellbeing society is proceeding to advance to give a more secure workplace to individuals working around electrical hardware. To enhance electrical security, it takes sense of duty regarding consistent change of the electrical wellbeing society. New musings and thoughts to enhance electrical wellbeing are basic. This paper addresses how function hones have changed after some time and prescribes thoughts to overhaul the current electrical culture. To change the current security culture new thoughts should be produced to cause higher execution in electrical wellbeing for all individuals presented to electrical risks. New circuit testers take in great and unfortunate propensities from more experienced circuit testers. Human execution depends on a mix of information, abilities, and educated practices. Convictions can be affected through perceptions and collaborations with different experts. The estimation of value mentorship conveys a high level of obligation to guarantee legitimate wellbeing rehearses is taken after. Almost no exertion has been given to preparing the nonelectrical labourers that are presented to electrical risks. Preparing for non-electrical labourers is a missing component in the present electrical security culture. A principal contention in this paper is that culture speaks to the entirety of what is regularly adequate without examination. The way of life is likewise determined by regular perception and experience. With a specific end goal to change the way of life there must be a redefinition of what is satisfactory, trailed by noticeable changes that everybody can understanding and watch. Administration possesses culture since it sets what is passable and satisfactory. Accordingly, the fate of electrical wellbeing will rely upon how well administration comprehends the hazard and results of electrical work and their duty in moulding and owning electrical security strategies. Enter components tended to in this paper incorporate human execution, innovation changes, adjusting to change, actualizing new thoughts to enhance security and how staff changes inside an enterprise can influence wellbeing execution.
\end{abstract}

Copyright (C) 2018 Institute of Advanced Engineering and Science. All rights reserved.

\section{Corresponding Author:}

Benjamin Franklin A,

Research Scholar, Department of Electrical and Electronics Engineering (Marine),

AMET University, Chennai

\section{INTRODUCTION}

"You are the ace of your fate. You can impact, direct, and control your own particular condition" Napoleon Hill.

\section{Problem Description}

Who changes the electrical wellbeing society inside your working environment? Whenever asked, workers regularly quality the obligation regarding electrical security culture to upper administration. From time to time do they trait it as their own duty. Basically, every individual is in charge of their wellbeing and 
in this manner must be a dynamic Member in the foundation and upkeep of the association's electrical security culture.

Electrical wellbeing societies are characterized by their ordinary recognizable acts and rehearsed rules. Consider changes to societies start with a consciousness of the requirement for change. Consciousness of changes and responsiveness to constant social changes ought to be met with good faith and openness. Eras basically think and act differently [1].

\section{Background}

In the current past, individuals utilized telephones to converse with each other. Presently, telephones are fundamentally used to content or email each other. In the event that you hope to change a culture, you should successfully impart to all eras in the workforce using different specialized strategies [2]. Cross generational groups might be a compelling device to guarantee that change can be acknowledged by all gatherings will's identity influenced by the new techniques. Having the capacity to speak with upper administration about the electrical security culture and its needs is a vital component to accepting administration bolster. Seeing how to pass on data to administration in money related terms; i.e., costinvestment funds, worker security, less generation days lost, zero fatalities, less dollars lost to forced fines or settlements, better wellbeing records, and so on can upgrade the practicality of having electrical wellbeing programs financed [3]. A Study on 3-phase Interleaved DC-DC Boost Converter Structure and Operation for Input Current Stress Reduction [11]. Hardware Implementation of Solar Based Boost to SEPIC Converter Fed Nine Level Inverter System [12]. Transformer Less Voltage Quadrupler Based DC-DC Converter with Coupled Inductor and PI Filter for Increased Voltage Gain and Efficiency [13]. Solar Photovoltaic array Fed Water Pump Riven by Brushless DC Motor Using KY Converter [14].

\section{WHERE WERE WE YESTERDAY?}

"You did then what you knew how to do, and when you knew better, you improved" Maya Angelou.

Numerous things have changed since the 60s. A standout amongst the most vital changes is in the outline of hardware. Figure 1 demonstrates a few cases of hardware outlined and introduced amid these years. Another change is the conviction that electrical hardware must be taken a shot at live and it was too expensive to de-energize the equipment [4]. Amid this time period it was normal practice to make grafts on 480 volt feeders without de-energizing. How individuals dressed when functioning close stimulated electrical gear is another case of changes in the electrical security culture [5].
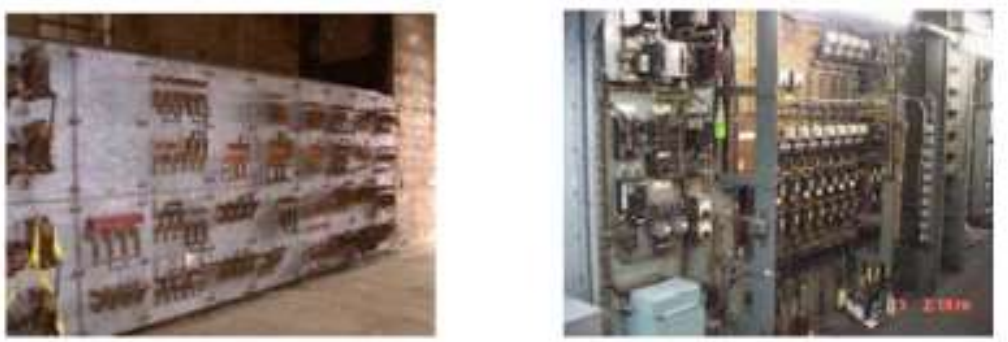

Figure 1. Equipment Designs in 50s and 60s

In the past it was regular to take a shot at invigorated electrical hardware in cotton attire, now and again circuit testers would be wearing a t - shirt or a polyester shirt. It was just in the 1990s when most circuit repairmen and others presented to stimulated electrical gear began wearing bend appraised attire to help shield them from circular segment streak perils. Beginning in the 70s, 80s, and 90s noteworthy changes have occurred to help change the electrical security culture. Organizations began requiring electrical safe work hone guidelines and electrical wellbeing preparing for their representatives. These protected work measures included prerequisites for the utilization of curve appraised attire, the utilization of extra PPE and protected apparatuses, and de-energizing electrical gear before begin of work. Many organizations electrical wellbeing societies enhanced after some time in view of a superior comprehension of electrical security. New guidelines and direction including an accentuation on electrical wellbeing works on, working de-energized, wearing PPE, and better outlined hardware were all key segments to increasing current standards in electrical security.

Indonesian J Elec Eng \& Comp Sci, Vol. 9, No. 1, January 2018 : 93-96 


\section{WHERE ARE WE TODAY?}

"The trouble lies, not in the new thoughts, but rather in getting away from the old ones." John Maynard Keynes.

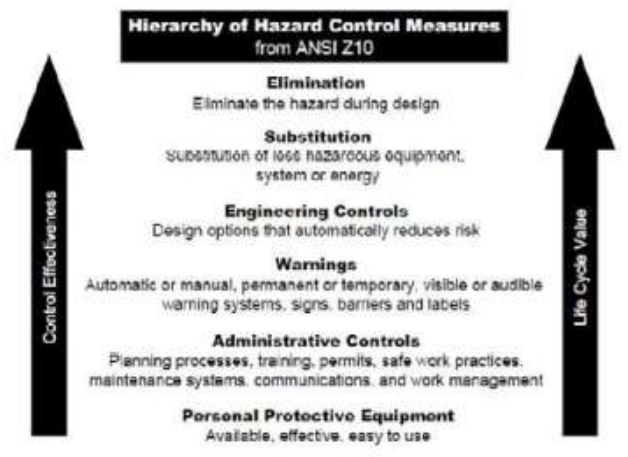

Figure 2. Hierarchy of Hazard Control Methods

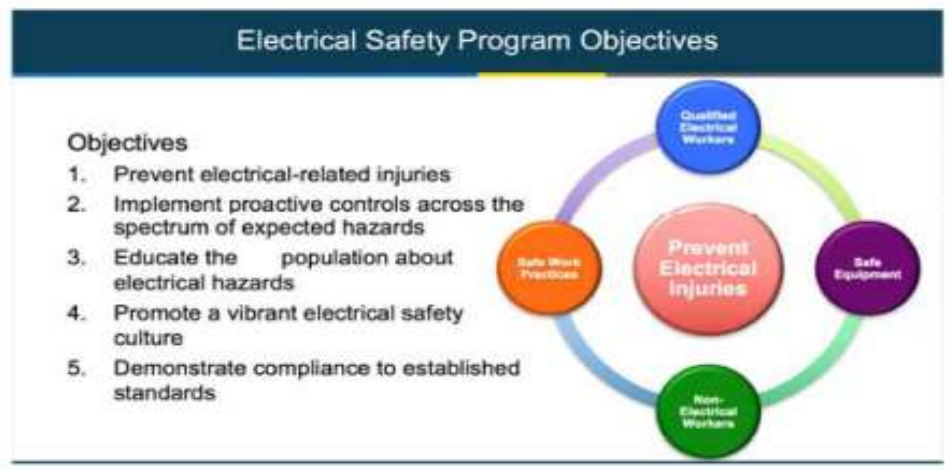

Figure 3. Example of an Electrical Safety Program's Objectives

NFPA 70E, OSHA, and the IEEE 1AS Electrical Safety Workshop meetings assumed a noteworthy part in changing how individuals think and act when functioning with and around electrical hardware [6]. The plan of electrical gear has rolled out huge improvements to enhance wellbeing. For instance, today one can buy circular segment safe hardware, gear that permits remote racking of circuit breakers, engine control focuses that are intended to permit addition and expulsion of the individual units without reaching the invigorated transport and brilliant transfers that can demonstration to limit the episode vitality amid blame. These are only a couple of cases of "Security by Design" being used today to help ensure individuals and hardware. A large portion of these "Wellbeing by Design" highlights are commanded in the electrical safe work rehearses guidelines that organizations have executed. The greater part of the previously mentioned things changed the electrical wellbeing society and changed how individuals think and act when functioning around electrical gear. In any case, enhancing and changing the electrical wellbeing society is a ceaseless procedure [7].

\section{WHERE WILL WE BE IN THE FUTURE?}

"Security is not a program. It is a pre-condition for authoritative conduct" Paul O'Neill.

One of the primary things to perceive is that a poor security culture can be settled, and a decent wellbeing society can turn out to be considerably more prominent. Regularly individuals will point to social issues as the hidden reason for poor execution. That is on account of a poor culture is something that is unimaginable for a solitary individual to overcome [8]. It at that point progresses toward becoming something you work around, something you wind up tolerating as an essential impediment to change. To change the electrical security culture this test must be met head on. Culture is characterized as the 
arrangement of shared mentalities, qualities, objectives, and practices that describes a foundation or association [9]. Put just, it is the arrangement of standards that everybody certainly consents to in light of the fact that they are seen practically speaking in regular daily existence. With regards to security culture, these standards will normally change after some time and over various areas, and between various professional workplaces. In Beliefs Drive Behaviours [10], the writers have effectively settled the accompanying:

- To decrease electrical wounds, you should figure out how to prevenU reduce hazardous practices.

- To address hazardous practices, you should change convictions.

In this paper, the creators expand on that contention and make the accompanying main issue, that to change convictions, you have to characterize, screen, and consistently enhance the Electrical Safety Culture.

\section{CONCLUSION}

The process of continuing to improve the electrical safety culture IS a never ending process. By looking back over time it is evident that there has been positive growth. People do things the best way they know how. People do learn. There is value in sharing what you know. Mentoring, benchmarking, and committee involvement all drive continuous improvement efforts. Mere compliance to regulations ignores decades of new knowledge, best practices, and other guides for safe work practices. A company with a strong electrical safety culture will understand that these are necessary for the protection of workers. They will educate their staff to ensure workplace electrical safety hazards are properly identified, analyzed, and effectively mitigated. Learning from others is the hallmark of a culturally effective electrical safety program. One hundred years ago there was no electricity in many homes. Today travel in space is possible, and wireless communications have transformed our society in the span of a couple of decades. People use and adapt to technology to create change. Future changes in electrical culture will include things we have not begun to consider. Every improvement relies on continued efforts and commitment of people within their companies. The strategies identified in this paper should enable you to adapt and change your electrical culture for the better. You can make a difference.

\section{REFERENCES}

[1] Joe Barrios and Katie Scarlett Reyes. Bridging the Gap: Using Technology to Capture the Old and Encourage the New. IEEE Industry Applications Magazine. 2016; 22(3); 40-44.

[2] Daniel H Pink. Drive: The Surprising Truth about What Motivates Us, Riverhead Books. Copyright 2009.

[3] Ray Crow D and Danny P Liggett. Beliefs Drive Behaviors. IEEE Transactions on Industry Applications. 2014; 50(2); 1530- 1536.

[4] Ray Crow D. Electrical Safety Leadership From the 1ih Man. IEEE Industry Applications Magazine. 2016; 22(3); 58-62.

[5] Daryld Ray Crow. Where Are You Now? Where Will You Be in the Future? Presentation at the 2006 IEEE lAS Electrical Safety Workshop.

[6] NFPA 70E Standard For Electrical Safety In The Workplace

[7] Encyclopedia Britannica, Inc. Encyclopedia Britannica, Inc. 07 Nov. 2010.

[8] Pragale R, Patel A, Bresden R. Arc Flash KPI Compliance at a Large Oil \& Gas Company, Presentation at the 2016 IEEE lAS Electrical Safety Workshop. Paper No. PCIC-2016-27.

[9] Lu K and Macnae J. The international campaign on intercomparison between electrodes for geoelectrical measurements. Exploration Geophysics, 1998; 29(4), 484-488.

[10] Sagadevan S, Das I, Pal K, Murugasen P and Singh P. Optical and electrical smart response of chemically stabilized graphene oxide. Journal of Materials Science: Materials in Electronics, pp.1-9.

[11] Harimon, M. A., Ponniran, A., Kasiran, A. N., \& Hamzah, H. H. (2017). A Study on 3-phase Interleaved DC-DC Boost Converter Structure and Operation for Input Current Stress Reduction. International Journal of Power Electronics and Drive Systems (IJPEDS), 8(4).

[12] Jasmine, D., \& Gopinath, M. (2016). Hardware Implementation of Solar Based Boost to SEPIC Converter Fed Nine Level Inverter System. International Journal of Power Electronics and Drive Systems, 7(4).

[13] Sujitha, C., Ravi, S., Diarra, B., \& Chuma, J. (2016). Transformer Less Voltage Quadrupler Based DC-DC Converter with Coupled Inductor and PI Filter for Increased Voltage Gain and Efficiency. International Journal of Power Electronics and Drive Systems, 7(4).

[14] Dinesh, B., Jaivinayagam, M., Udayakumar, M., \& Syedismail, S. Solar Photovoltaic Array Fed Water Pump Riven by Brushless DC Motor Using KY Converter. 